\title{
Notes on Parturition of an Indian Vine Snake, Ahaetulla nasuta (Lacépède 1789) (Squamata: Ahaetuliidae) in Captivity
}

\author{
Khan Ashaharraza $^{1}$ and Shubham Sayanke ${ }^{2}$ \\ 1'Indian Herpetological Society, Pune- 411009, Maharashtra, India (ashaharrazakhan@gmail.com) \\ ${ }^{2}$ New plots of Uttamsara, Tq-Bhatkuli, Amravati- 444701, Maharashtra, India
}

$\mathrm{T}$

The Indian Vine Snake (Ahaetulla nasuta) is widely distributed throughout peninsular India, including some parts of Gujarat (Vyas 2013) and Rajasthan (Sharma 1995) but is absent from the extreme northwestern parts of the country and from the Gangetic Basin (Whitaker and Captain 2008). Although the senior author found this species to be relatively common in the dense forests of Amravati, it was considered to be uncommon or rare in the district by Nande and Deshmukh (2007).

This species bears live young and the gestation period can be as long as 172 days (Daniel 2002). However, Anil Khaire (pers. comm.) observed a period of only 51 days. As many as
23 young are born between March and December (Whitaker and Captain 2008) with total lengths of neonates measuring 200-440 mm (Das 2012).

An adult Indian Vine Snake (Fig. 1) was collected by the second author during a rescue operation at $0930 \mathrm{~h}$ on 28 May 2014 from the hedge of the Social Forestry Plantation at Uttamsara (2051'41.5"N 77³9'37.6"E), Bhatkuli, Amravati District. After observing the distended posterior body (Fig. 2), the snake was referred to the senior author, who concluded that it was a gravid female. Total length was $1,003 \mathrm{~mm}$, snout-vent length (SVL) $640 \mathrm{~mm}$, and tail length

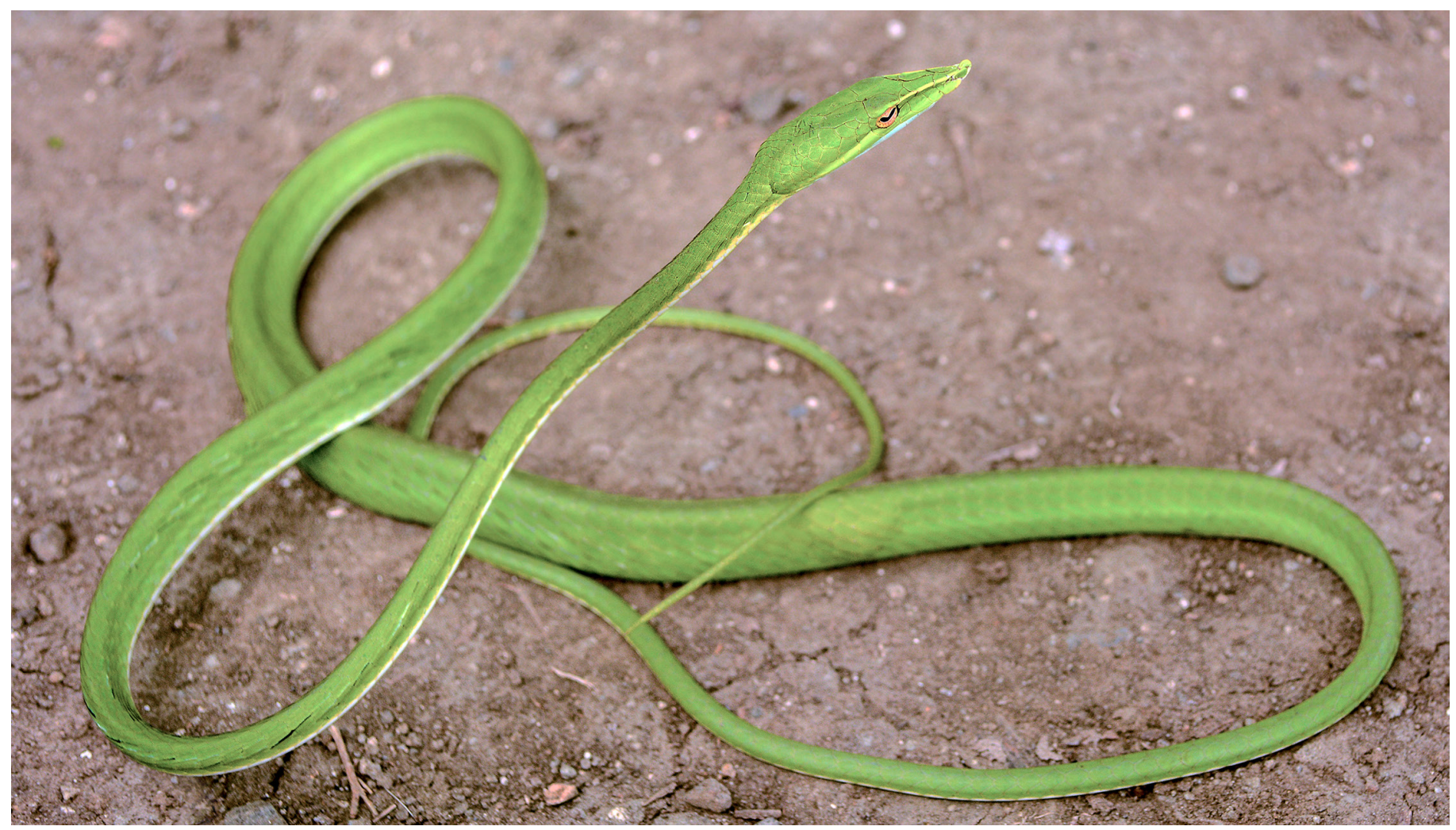

Fig. 1. A gravid female Indian Vine Snake (Ahaetulla nasuta). Photograph by Khan Ashaharraza. 


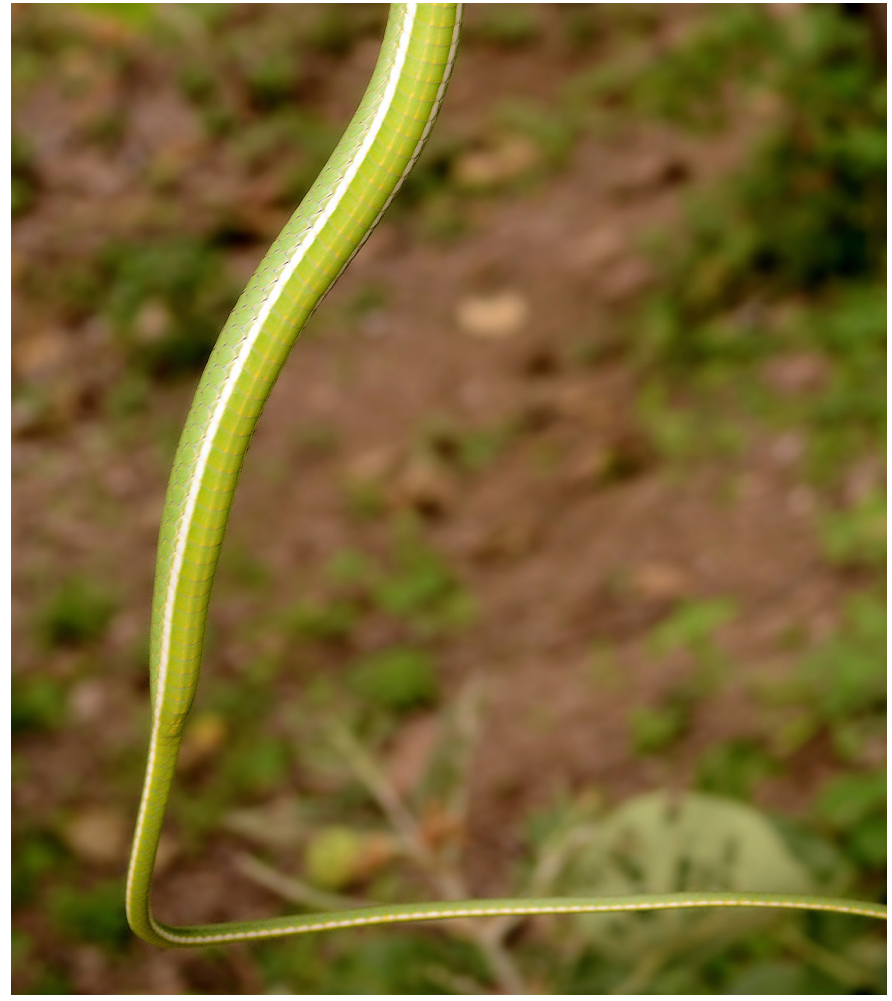

Fig. 2. Noticeable bulging in the posterior body of a gravid female Indian Vine Snake (Ahaetulla nasuta). Photograph by Khan Ashaharraza.
(TL) $390 \mathrm{~mm}$. The distended girth indicated that the female was ready to deliver. It was housed in a glass box $(90 \times 30 \times$ $45 \mathrm{~cm}$ ) and provided with twigs for perching and a bowl of water. The substrate was oven-dried to avoid any contamination and temperature was maintained at a constant $30.0^{\circ} \mathrm{C}$.

The snake initially accepted two Graceful Leaf-toed Geckos (Hemidactylus gracilis) and an Indian Burrowing Frog (Sphaerotheca cf. breviceps) but soon began to refuse offered prey items and become noticeably less active. Parturition began at $2315 \mathrm{~h}$ on 16 August, 77 days after the female was captured, and by $0545 \mathrm{~h}$ on 17 August four neonates (Fig. 3), all apparently healthy, had been delivered. Total lengths of the neonates ranged from 240 to $285 \mathrm{~mm}$, with SVL averaging $181.3 \mathrm{~mm}$ $(170-190 \mathrm{~mm})$ and TL $82.5 \mathrm{~mm}(70-95 \mathrm{~mm})$. The snakes were photographed and released into natural habitat in the presence of Maharashtra Forest Department authorities.

By examining museum specimens and snakes in the field, we have noticed that individuals of widely distributed Indian snakes in central India are smaller and appear to attain sexual maturity sooner than individuals of the same species from other parts of the country. As far as we know, this is the first description of parturition in this species from central India; extensive surveys and considerably more data will be required to determine if our observations hold true for Ahaetulla nasuta.

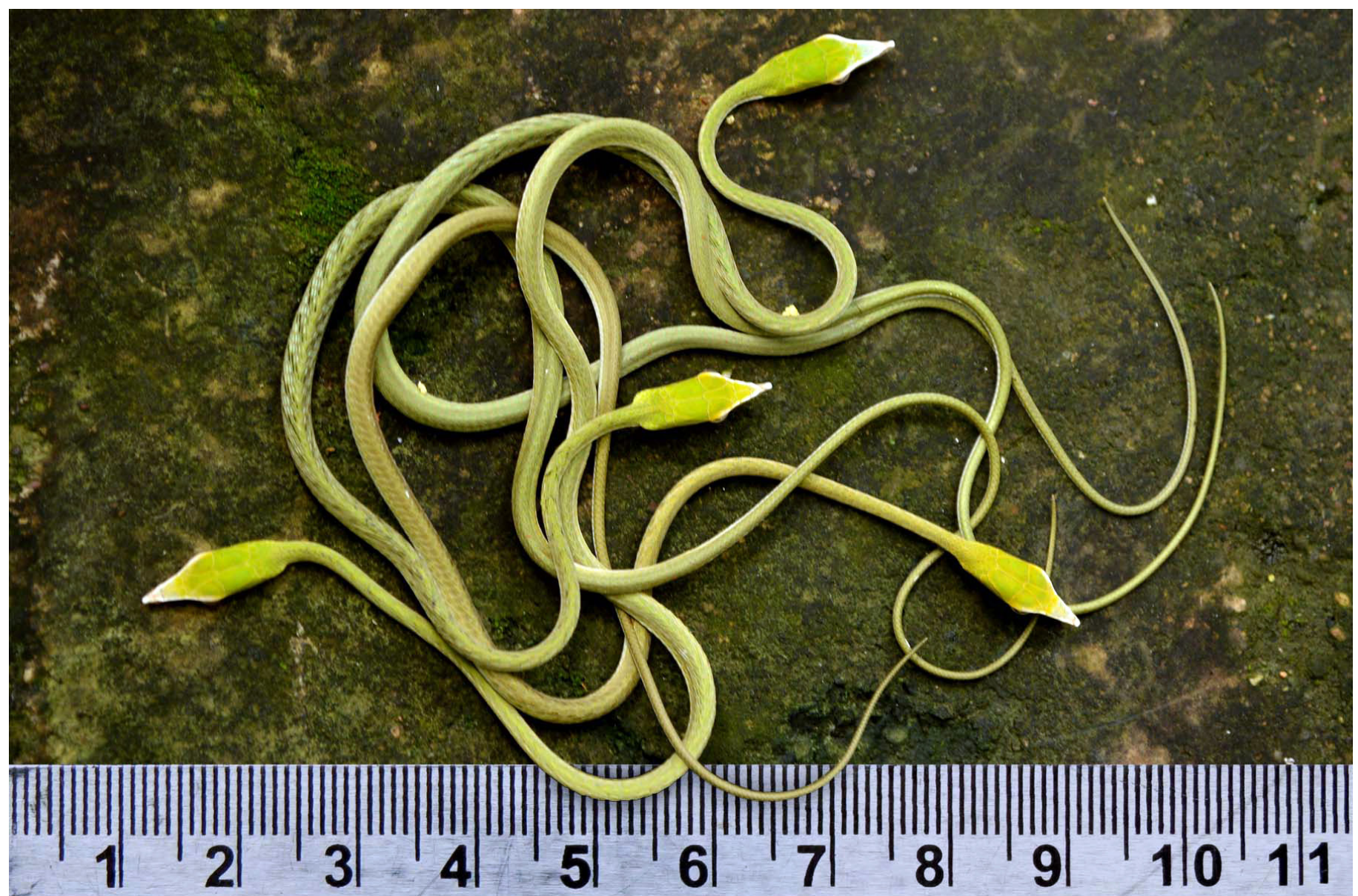

Fig. 3. Hatching Indian Vine Snakes (Ahaetulla nasuta). Photograph by Khan Ashaharraza. 


\section{Acknowledgments}

Ninu Somraj (former Divisional Forest Officer, Amravati) and Pradeep Lakde (former Range Forest Officer, Wadali Range) provided guidance and permission to conduct this study. Anil Khaire reviewed an earlier version of this manuscript. Manoj Bind helped with photographs. KA also thanks Peter Uetz (Center for the Study of Biological Complexity, Virginia Commonwealth University, Richmond, Virgina, USA) for help with the literature. SS is thankful to Gajendrasingh Pachlore (Vinayak Vidya Mandir). Ahsan Sheikh and Mukesh Malave helped in many ways.

\section{Literature Cited}

Daniel, J.C. 2002. The Book of Indian Reptiles and Amphibians. Oxford University Press, Oxford, UK.

Nande, R. and S. Deshmukh. 2007. Snakes of Amravati District including Melghat, Maharashtra with important records of the Indian Egg-Eater, Montane Trinket Snake and Indian Smooth Snake. Zoos' Print Journal 22: 2920-2924.

Sharma, S.K. 1995. Presence of Common Green Whip Snake Ahaetulla nasutus at "Phulwari Ki Nal" Wildlife Sanctuary in Rajasthan. Journal of the Bombay Natural History Society 92: 127.

Vyas, R. 2013. Snake diversity and voluntary rescue practice in the cities of Gujarat State, India: An evaluation. Reptile Rap 15: 27-39.

Whitaker, R. and A. Captain. 2008. Snakes of India. The Field Guide. Draco Books, Chennai, India. 